\title{
Hijab dan Niqab: Kewajiban ataukah Anjuran? (Analisis Pemikiran Muhammad Ali al-Shabuni dan Muhammad Quraish Shihab Tentang Jilbab dan Niqab)
}

\author{
Siti Ngainnur Rohmah, ${ }^{1}$ Imam Prawoto ${ }^{2}$ \\ Institut Agama Islam Al Zaytun Indonesia \\ https://doi.org/10.32507/mizan.v4i1.599
}

\begin{abstract}
The majority of scholars agree that wearing the hijab is mandatory for every Muslim, both Arabs and non-Arabs. On the other hand, some scholars believe that wearing the hijab is not mandatory. This is based on the understanding that not all verses that contain commands mean commands, but they can also mean suggestions. This paper presents the interpretation of the Qur'anic verses about the hijab and purdah. There are two interpretations used as the main objects in this study, namely Shafwah al-Tafasir by Muhammad 'Ali al-Shabuni and Tafsir al-Mishbah by Muhammad Quraish Shihab. The research method used is qualitative with a literature approach. This paper will analytically describe and critically explore the views of Muhammad 'Ali al-Shabuni and Muhammad Quraish Shihab about the hijab and purdah.
\end{abstract}

Keywords: Hijab, Purdah, Obligations, Recommendations

\begin{abstract}
Abstrak
Mayoritas ulama sepakat bahwa memakai jilbab adalah wajib bagi setiap muslimah, baik orang Arab maupun orang 'Ajam. Di sisi lain sebagian ulama berpendapat bahwa memakai jilbab tidak wajib. Hal ini berdasarkan pemahaman bahwa tidak semua ayat yang mengandung perintah bermakna perintah, namun bisa juga bermakna anjuran. Tulisan ini menyajikan penafsiran ayat-ayat Alquran seputar jilbab dan cadar. Ada dua buah tafsir yang dijadikan objek utama dalam penelitian ini, yaitu Shafwah al-Tafasir karya Muhammad 'Ali al-Shabuni dan Tafsir al-Mishbah karya Muhammad Quraish Shihab. Metode penelitian yang digunakan adalah kualitatif dengan pendekatan literatur. Tulisan ini akan mendeskripsikan secara analitis dan mengeksplorasi secara kritis pandangan Muhammad 'Ali al-Shabuni dan Muhammad Quraish Shihab seputar jilbab dan cadar.
\end{abstract}

Kata Kunci: Jilbab, Cadar, Kewajiban, Anjuran Maret 2020.

* Naskah diterima tanggal: 14 Januari 2020, direvisi: 16 Februari 2020, disetujui untuk terbit: 2

${ }^{1}$ Siti Ngainnur Rohmah adalah Dosen di Institut Agama Islam Al Zaytun Indonesia. Mekarjaya, Gantar, Indramayu, Jawa Barat. E-mail: siti.ngainnur@iai-alzaytun.ac.id.

${ }^{2}$ Imam Prawoto adalah Dosen di Institut Agama Islam Al Zaytun Indonesia. Mekarjaya, Gantar, Indramayu, Jawa Barat. E-mail: imam.prawoto@iai-alzaytun.ac.id. 


\section{A. PENDAHULUAN}

Hijab dewasa ini menjadi tren yang fenomenal pada masyarakat Indonesia. Hijab seringkali diidentikkan dengan jilbab. Jilbab berarti selendang yang lebih lebar daripada kerudung. ${ }^{3}$ Jilbab juga berarti kain yang dapat dilipatkan. ${ }^{4}$ Jilbab juga berarti pakaian yang menutup seluruh tubuh wanita mulai dari kepala sampai ujung kaki yang terlihat hanya dua matanya saja. ${ }^{5}$ Sedangkan cadar adalah penutup kepala yang menutupi bagian wajah, namun masih membiarkan bagian mata terbuka. Cadar pada umumnya menjuntai hingga bagian tengah punggung dan menutupi bagian tengah dada. ${ }^{6}$

Tulisan ini akan menjelaskan beberapa ayat yang terkait dengan jilbab dan cadar. Benarkah memakai jilbab dan cadar adalah kewajiban bagi setiap muslimah? Adakah model penafsiran lain terhadap ayat-ayat seputar jilbab dan cadar? Bagaimana memahami dan menyikapi ragam penafsiran yang secara eksplisit mengatakan bahwa menggunakan jilbab bagi kaum wanita tidak wajib? Tulisan ini diharapkan bisa menjadi salah satu bahan acuan untuk mengetahui ragam penafsiran ayat-ayat tentang jilbab dan cadar.

Sumber utama tafsir yang dipergunakan dalam tulisan ini adalah Shafwah alTafasir' karya Muhammad 'Ali al-Shabuni' dan Tafsir al-Mishbah' karya Muhammad Quraish Shihab. ${ }^{10}$ Pendekatan yang digunakan dalam tulisan ini adalah pendekatan interpretasi (interpretative approach), yakni menyelami pemikiran seorang tokoh yang tertuang dalam karya-karyanya, khususnya Tafsir Shafwah al-Tafasir dan Tafsir alMishbah, untuk menangkap nuansa makna dan pengertian yang dimaksud secara khas sehingga tercapai suatu pemahaman yang utuh dan benar. Artikel ini menggunakan metode kualitatif sebagai analisis data. Di samping itu, peneliti juga menggunakan pendekatan komparatif yaitu membandingkan pendapat Muhammad 'Ali al-Shabuni dan Muhammad Quraish Shihab tentang ayat-ayat jilbab dan cadar, juga mengkomparasikannya dengan beberapa tafsir yang lainnya.

\section{B. METODE PENELITIAN}

Makalah ini menggunakan teknik analisis hukum normatif yaitu penelitian hukum yang dilakukan melalui studi pustaka dokumen atau alat bukti sekunder

${ }^{3}$ Menurut Ibnu Mas'ud, Ubaidah, Qatadah sebagaimana yang dikutip oleh Ibnu Katsir dalam Mukhtashar Ibnu Katsir, 901..

${ }^{4}$ Al-Jauhari sebagaimana yang dikutip oleh Ibnu Katsir dalam Mukhtashar Ibnu Kathir, 901.

${ }^{5}$ Ali bin Abi Talhah meriwayatkan dari Ibnu Abbas.

${ }^{6}$ Muhammad 'Ali Al-Shabuni, Rawai' al-Bayan Tafsīr Ayat al-Ahkām min al-Qur'an (Jakarta: Dar alKutub al-Islamiyyah, 1999), II, 92-95.

${ }^{7}$ Metode yang digunakan dalam Shafwah al-Tafasir, adalah memakai metode tahlili.

8 Muhammad 'Ali Al-Shabuni lahir di kota Halb/Aleppo Syiria pada tahun 1930 M. Beliau mempunyai nama lengkap Muhammad bin 'Ali bin Jamil Al-Shabuni. Sejak kecil ia sudah terlihat bakat dan kecerdasannya dalam menyerap berbagai ilmu agama dan hafal Al-Qur'an.

${ }^{9}$ Metode yang digunakan dalam tafsir al-Misbah adalah memakai metode tahlili.

${ }^{10}$ Muhammad Quraish Shihab lahir di Rappang Sulawesi Selatan pada tanggal 16 Februari 1944. Ayahnya bernama 'Abdur Rahman Shihab (1905-1986) adalah alumni Jam'iyyat al-Khair Jakarta. 
sebagai tugas pokoknya. Analisis hukum normatif merupakan metode penelitian ilmiah untuk menemukan fakta berdasarkan penalaran ilmiah hukum dari sudut pandang normatif (Soekanto, 2015: 13-14). Dengan demikian kajian ini berangkat dari perspektif asas hukum positif terkait dengan kerangka hukum nasional dan peraturan perundang-undangan (Marzuki, 2016: 59). Metode hukum dan pendekatan kasus adalah metode yang digunakan. Alat bukti sekunder terutama diambil dari peraturan perundang-undangan tentang pemberantasan perbuatan salah dan putusan pengadilan sebagai bahan hukum utama. Data yang terkumpul kemudian dianalisis secara kualitatif.

\section{ANALISIS DAN PEMBAHASAN}

Dahulu wanita muslim dan non muslim berpakaian sama yaitu memakai baju dan kerudung namun masih terlihat dada, telinga, dan leher. Hal ini menyebabkan orang-orang munafik mengganggu seorang muslimah jika mereka keluar rumah. Oleh karena itu Allah memerintahkan seorang muslimah agar mengulurkan jilbab hingga ke dada. Hal ini dimaksudkan supaya wanita muslimah lebih dikenal dan tidak diganggu.

Mayoritas ulama berpendapat bahwa memakai jilbab adalah wajib. Jilbab adalah identitas seorang muslimah. Selain itu mengenakan jilbab juga dapat menghindarkan diri dari gangguan dan godaan laki-laki. Hal ini didasarkan pada firman Allah SWT dalam Q.S. Al-Ahzab ayat 59 :

"Hai Nabi, Katakanlah kepada isteri-isterimu, anak-anak perempuanmu dan isteri-isteri orang mukmin: "Hendaklah mereka mengulurkan jilbabnya ke seluruh tubuh mereka". yang demikian itu supaya mereka lebih mudah untuk dikenal, karena itu mereka tidak di ganggu. dan Allah adalah Maha Pengampun lagi Maha Penyayang."

Muhammad bin Sirin mengatakan, bahwa ia bertanya kepada Ubaidah alSalmani tentang firman Allah, 'hendaklah mereka mengulurkan jilbabnya ke seluruh tubuh mereka.' Dia berkata, 'yaitu menutup wajah, kepala, dan hanya boleh menampakkan mata kirinya saja.'" Ikrimah berkata. "berarti wanita harus menutupi lehernya dengan jilbab yang dilipatkan ke dadanya. Ibnu Abi Hatim meriwayatkan dari Ummu Salamah, dia berkata, "Setelah Q.S Al-Ahzab ayat 59 turun, maka kaum wanita Anshar keluar rumah dan seolah-olah di kepala mereka terdapat sarang burung gagak. Mereka pun mengenakan baju hitam."11 Jika kita cermati hadits di atas maka yang dimaksud jilbab pada Q.S Al-Ahzab ayat 59 ini adalah cadar. Namun para ulama berselisih pendapat tentang hal ini.

Ayat di atas menjelaskan tentang kewajiban muslimah untuk memakai jilbab. Bahkan sebagian ulama mewajibkan untuk memakai cadar. Muhammad 'Ali AlShabuni berpendapat bahwa Allah memerintahkan para istri Nabi, dan para muslimah untuk memakai jilbab yang lebar dan menutupi kecantikan serta perhiasan mereka,

\footnotetext{
${ }^{11}$ Ibnu Kathir, Mukhtashar Ibnu Kathir, 901.
} 
menolak lidah buruk dari mereka, dan membedakan mereka dari wanita jahiliyah. ${ }^{12}$ Beliau mengutip riwayat Ibnu 'Abbas bahwa jika seorang muslimah keluar rumah untuk suatu keperluan agar mereka menutupi wajah mereka dari atas kepala dengan jilbab dan hanya menampakkan satu mata. Nash dari Ibnu 'Abbas ini menunjukkan wajibnya menutup wajah.

Syariat jilbab ini bukan berasal dari tradisi orang Arab atau ber-taqlid kepada umat sebelumnya seperti yang dianggapkan oleh sebagian orang. ${ }^{13}$ Hal ini sesuai dengan asbabunnuzul ayat ini yang diriwayatkan oleh al-Suddi, bahwasanya orangorang fasik mengganggu para wanita jika keluar rumah di malam hari. Jika mereka melihat wanita memakai cadar, mereka membiarkannya, karena mereka tahu itu adalah wanita merdeka. Jika mereka melihat wanita itu tidak memakai cadar, mereka mengganggunya karena wanita itu dikiranya budak wanita. ${ }^{14}$ Ada riwayat lain yang dikemukakan oleh Abi Malik, bahwasanya ketika wanita yang beriman keluar rumah pada malam hari karena suatu hajat, mereka diganggu oleh orang-orang munafik, lalu turunlah ayat ini. ${ }^{15}$

Ayat di atas dipertegas oleh Q.S. An-Nur ayat 31,

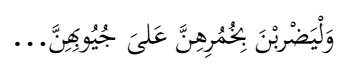

"..dan hendaklah mereka menutupkan kain kerudung kedadanya,..."

Kata khumur adalah jamak dari khimar yang berarti sesuatu yang menutupi kepala wanita dan menutupinya dari pandangan laki-laki. Sedangkan kata juyub adalah bentuk jamak dari jayb yaitu yang berarti dada. Ayat di atas memerintahkan para muslimah untuk memakai kerudung hingga menutupi dada mereka, agar dada mereka tidak kelihatan sama sekali. ${ }^{16}$

Aisyah R.A. berkata, "Allah memberikan rahmat kepada wanita-wanita yang pertama kali melakukan hijrah, ketika Allah menurunkan firman-Nya,' dan hendaklah mereka menutupkan kain kerudung ke dadanya, dan janganlah menampakkan perhiasannya,' di mana mereka mengalami kesulitan, namun mereka tetap memakainya." ${ }^{17}$ Hadits tersebut diperkuat oleh ayat, "dan janganlah mereka menampakkan perhiasannya, kecuali yang (biasa) nampak dari padanya." Ayat ini merupakan dalil atas pentingnya menutup aurat secara penuh, dan mereka diharamkan mempertontonkan perhiasannya. Anggota badan seperti lengan, pinggang, dan dada merupakan anggota badan yang paling haram dipertontonkan. Ini berarti mereka tidak boleh membuka anggota badan tersebut di

${ }^{12}$ Muhammad 'Ali al-Shabuni, Shafwah al-Tafasir Kairo: Dar al-Shabuny, 1980, Jilid II, 516-517.

${ }^{13}$ Muhammad 'Ali Al-Shabuni, Cahaya Al-Qur'an Jakarta: Pustaka Al-Kauthar, 2002, Jilid 5, 42.

${ }^{14}$ Pada saat ayat ini diturunkan kondisi di lingkungan Arab wanita merdeka memakai cadar, sedangkan para budak tidak memakai cadar. Muhammad 'Ali al-Shabuni, Shafwah al-Tafasir Kairo: Dar alShabuny, 1980, Jilid II, 517

${ }^{15}$ Lihat Al-Wāhidī (Abū al-Hasan 'Ali bin Ahmad al-Nahwī), Asbāb al-Nuzūl, 235; disebutkan oleh al-Suyuti dalam al-Lubab; Ibnu Sa'id dalam al-Thabaqat.

${ }^{16}$ Muhammad 'Ali Al-Shabuny, Cahaya Al-Qur'an, 42.

${ }^{17}$ Hadith ini ditakhrij oleh Bukhary di dalam kitab Al-Tafsir, VIII, 489 dari kitab Fath al-Bari. Lihat juga hadith-hadith yang ada di dalam Tafsir Ibnu Kathir, III, 295. 
hadapan laki-laki yang bukan mahramnya. Sebagian ulama berpendapat bahwa perhiasan itu adalah wajah dan dua telapak tangan.

Dari nash-nash dan uraian di atas dapat kita ketahui bahwa jilbab diwajibkan atas seorang muslimah dengan nash-nash di dalam kitab Allah secara qath'iyud dilalah, dan sekaligus membantah pendapat yang menyatakan bahwasannya jilbab adalah adat kebiasaan orang Arab yang diterapkan pada masa Abbasiyah. Di balik kewajiban mengenakan jilbab, Islam ingin memotong jalan keraguan dan tipu daya syetan untuk berputar-putar di dalam hati laki-laki dan perempuan. Hal ini bertujuan untuk menjaga kemuliaan, kesucian, dan kehormatan mereka.

Dalam menafsirkan ayat di atas, Muhammad Quraish Shihab memiliki pandangan bahwa Allah tidak memerintahkan seorang muslimah memakai jilbab. Pendapatnya tersebut ialah sebagai berikut: "Ayat di atas tidak memerintahkan wanita muslimah memakai jilbab, karena agaknya ketika itu sebagian mereka telah memakainya, hanya saja cara memakainya belum mendukung apa yang dikehendaki ayat ini. Kesan ini diperoleh dari redaksi ayat di atas yang menyatakan jilbab mereka dan yang diperintahkan adalah "Hendaklah mereka mengulurkannya." Nah, ini perintah terhadap mereka yang telah memakai jilbab, tentu lebih-lebih lagi yang belum memakainya, Allah berfirman: "Hendaklah mereka mengulurkan jilbabnya."18

Di samping mengulangi pandangannya tersebut ketika menafsirkan Q.S AnNur ayat 31, Muhammad Quraish Shihab juga mengulanginya dalam buku Wawasan Al-Qur'an. Ia bahkan mempertanyakan hukum jilbab dengan mengatakan bahwa tidak diragukan lagi bahwa jilbab bagi wanita adalah gambaran identitas seorang muslimah. Boleh saja mengatakan menutup aurat seluruh tubuh kecuali wajah dan telapak tangan menjalankan bunyi teks ayat itu. Namun pada saat yang sama tidak wajar menyatakan mereka yang tidak berkerudung secara pasti telah melanggar petunjuk agama. AlQur'an juga tidak menyebut batas aurat secara jelas. Para ulama ketika membahasnya pun juga berbeda pendapat. ${ }^{19}$

Berkaitan dengan ajaran jilbab, ini adalah ajaran yang mempertimbangkan adat orang-orang Arab, sehingga bangsa-bangsa lain yang tidak menggunakan jilbab, tidak terkena ketentuan perintah berjilbab ini. ${ }^{20}$ Pendapat ini senada dengan Muhammad Thahir bin Ashur yang berpendapat bahwa cara memakai jilbab berbeda-beda sesuai dengan perbedaan keadaan wanita dan adat istiadat mereka. Tetapi tujuan perintah ayat ini adalah seperti bunyi ayat itu yakni agar mereka dapat dikenal sebagai seorang muslimah yang baik.

Muhammad Qurash Shihab berpendapat bahwa tidak semua perintah dalam Al-Qur'an berarti perintah yang wajib dikerjakan. Akan tetapi sebagian bersifat anjuran. Contohnya perintah menulis hutang piutang dalam Q.S Al-Baqarah ayat 282.

${ }_{18}$ M. Quraish Shihab, Tafsir al-Mishbah, Pesan, Kesan, dan Keserasian al-Qur'an, Jakarta: Lentera Hati, 2002, Vol. 10, 429.

${ }^{19}$ M. Quraish Shihab, Wawasan al-Qur'an, Jakarta: Mizan, 1998, 179.

${ }^{20}$ M. Quraish Shihab, Wawasan al-Qur'an, 179. 
Menurutnya Q.S. Al-Ahzab ayat 59 itu juga hanya bersifat anjuran. ${ }^{21}$ Muhammad Quraish Shihab juga menulis hal ini ketika menafsirkan Q.S An-Nur ayat 31.

"Katakanlah kepada wanita yang beriman: "Hendaklah mereka menahan pandangannya, dan kemaluannya, dan janganlah mereka menampakkan perhiasannya, kecuali yang (biasa) nampak dari padanya. dan hendaklah mereka menutupkan kain kudung kedadanya,..."

Para wanita berkewajiban memelihara perhiasannya sehingga tidak terlihat kecuali yang biasa nampak darinya (illa maa dhahara minha). Penggalan ayat ini diperselisihkan maknanya oleh para ulama, khususnya makna kata illaa. Ada yang berpendapat bahwa kata illaa adalah istitsnaa' muttashil (satu istilah dalam bahasa Arab) yang berarti "Yang dikecualikan merupakan bagian/jenis dari apa yang disebut sebelumnya", dan yang dikecualikan dalam penggalan ayat ini adalah zinah atau hiasan. Ini berarti ayat tersebut berpesan: "Hendaknya janganlah wanita-wanita menampakkan hiasan (anggota tubuh) mereka, kecuali apa yang tampak."

Pertama, memahami kata illaa dalam arti tetapi atau dalam istilah bahasa Arab istitsnaa' munqaathi' dalam arti yang dikecualikan bukan bagian/jenis yang disebut sebelumnya. Ini bermakna: Janganlah mereka menampakkan perhiasan mereka sama sekali; tetapi apa yang nampak (secara terpaksaltidak sengaja)-seperti ditiup angin dan lain sebagainya, maka itu dapat dimaafkan.22

Kedua, menyisipkan kalimat dalam penggalan ayat itu. Kalimat yang dimaksud menjadikan penggalan ayat ini mengandung pesan lebih kurang: "Janganlah mereka (wanita-wanita) menampakkan perhiasan (badan mereka). Mereka berdosa jika berbuat demikian. Tetapi jika tampak tanpa disengaja, maka mereka tidak berdosa." 23

Ketiga, memahami firman-Nya " kecuali apa yang tampak" dalam arti yang biasa dan atau dibutuhkan keterbukaannya sehingga harus tampak. Kebutuhan di sini dalam arti menimbulkan kesulitan bila bagian badan tersebut ditutup. Mayoritas ulama memahami penggalan ayat ini dalam arti yang ketiga. Cukup banyak hadits yang mendukung pendapat ini. Misalnya: "Tidak dibenarkan seorang yang beriman kepada Allah dan hari kemudian untuk menampakkan kedua tangannya, kecuali sampai di sini (Nabi kemudian memegang setengah tangan beliau)" (H.R al-Thabary). ${ }^{24} \mathrm{Hal}$ tersebut mengemukakan bahwa zinah adalah sesuatu yang menjadikan sesuatu yang lain indah yakni hiasan. Sementara ulama membagi perhiasan ke dalam dua macam:

Pertama, hiasan yang bersifat khilqiyyah (fisik melekat pada diri seseorang). Menurut Ibnu Ashur yang bersifat fisik melekat adalah wajah, telapak tangan, dan setengah dari kedua lengan. Pakar hukum Ibnu 'Arabi berpendapat bahwa hiasan yang bersifat khalqiyyah adalah sebagian besar jasad perempuan, khususnya wajah dan kedua pergelangan tangannya, kedua siku sampai dengan bahu, payudara, kedua betis dan rambut. ${ }^{25}$

${ }^{21}$ M. Quraish Shihab, Wawasan al-Qur'an, 179.

22 ibid, 174.

${ }^{23}$ M. Quraish Shihab, Tafsir al-Mishbah, Pesan, Kesan, dan Keserasian al-Qur'an, vol. 9. 329-330.

${ }^{24}$ M. Quraish Shihab, Tafsir al-Mishbah, Pesan, Kesan, dan Keserasian al-Qur'an, Vol. 9, 330.

${ }^{25}$ Ibid, Vol. 9, 331. 
Kedua, hiasan yang bersifat muktasabah (yang dapat diupayakan). Menurut Ibnu Ashur yang bersifat muktasabah adalah pakaian yang indah, perhiasan, celak mata dan pacar. Al-Qur'an menggunakan kata zinah dalam arti pakaian, yaitu pada Q.S. AlA'raf ayat $31 .{ }^{26}$ Sedangkan menurut Ibnu 'Arabi hiasan yang bersifat dapat diupayakan adalah hiasan yang merupakan hal-hal yang lumrah dipakai sabagai hiasan buat perempuan, yakni perhiasan, pakaian indah dan berwarna warni, pacar, celak, siwak dan sebagainya.

Syeikh Muhammad 'Ali al-Sais, Guru besar Universitas al-Azhar Mesir, mengemukakan dalam tafsirnya bahwa Abu Hanifah berpendapat bahwa kedua kaki juga bukan aurat. Abu Hanifah mengajukan alasannya bahwa ini lebih menyulitkan bila harus ditutup dibandingkan tangan, khususnya bagi wanita-wanita miskin di pedesaan yang ketika itu sering berjalan tanpa alas kaki untuk memenuhi kebutuhan mereka.

Al-Qur'an memang mengajarkan bahwa kesulitan adalah faktor yang menyebabkan munculnya kemudahan. Secara tegas Al-Qur'an menyatakan bahwa:

"...Allah tidak hendak menyulitkan kamu sedikitpun,..." (Q.S. Al-Maidah: 6), dan bahwa:

"...Allah menghendaki kemudahan bagimu, dan tidak menghendaki kesukaran bagimu..." (Q.S. al-Baqarah: 185).

Menurut Ibnu 'Atiyah sebagaimana dikutip Muhammad Quraish Shihab berpendapat wanita diperintahkan untuk tidak menampakkan dan berusaha menutup segala sesuatu yang berupa hiasan. Pengecualian itu menurutnya berdasarkan keharusan gerak menyangkut hal-hal yang mesti, atau untuk perbaikan sesuatu dan semacamnya.

Di akhir tulisan tentang jilbab, Muhammad Quraish Shihab menyimpulkan:

"Memang, kita boleh berkata bahwa yang menutup seluruh badannya kecuali wajah dan (telapak) tangannya, menjalankan bunyi teks ayat itu, bahkan mungkin berlebih. Namun dalam saat yang sama kita tidak wajar menyatakan terhadap mereka yang tidak memakai kerudung, atau yang menampakkan tangannya, bahwa mereka "secara pasti telah melanggar petunjuk agama." Bukankah Al-Quran tidak menyebut batas aurat? Para ulama pun ketika membahasnya berbeda pendapat."

Jadi Muhammad Quraish Shihab menyimpulkan bahwa ayat-ayat mengenai jilbab tersebut tidak bersifat perintah tapi hanya sekedar anjuran saja. Karena pada dasarnya masyarakat Arab pada waktu itu sudah memakai kerudung tapi pemakaiannya belum sempurna. Maka dari itu Allah memerintahkan mereka supaya menyempurnakan pemakaiannya yaitu hingga menutup dada. Hal ini juga sebagai

${ }^{26}$ Q.S. Al-A'raf [7]: 31,

“Hai anak Adam, pakailah pakaianmu yang indah di setiap (memasuki) masjid [tiap-tiap akan mengerjakan sembahyang atau thawaf keliling ka'bah atau ibadat-ibadat yang lain], Makan dan minumlah, dan janganlah berlebih-lebihan [janganlah melampaui batas yang dibutuhkan oleh tubuh dan jangan pula melampaui batas-batas makanan yang dihalalkan]. Sesungguhnya Allah tidak menyukai orang-orang yang berlebih-lebihan". 
identitas agar seorang muslimah lebih dikenal dan tidak diganggu. Sedangkan untuk masyarakat non Arab tidak wajib mengenakan jilbab karena tidak sesuai dengan budaya setempat. Jika hal ini dipaksakan akan menyebabkan ketidaknyamanan bagi pemakainya.

Muhammad 'Ali Al-Shabuni dalam memahami Q.S. Al-Ahzab ayat 59 ini menggunakan kaidah tafsir al-'ibrah bi 'umum al-lafz wa bi khusush al-sabab. Jadi, ayat ini berlaku untuk orang-orang yang terlibat dalam latar belakang ayat itu ketika diturunkan, yaitu wanita-wanita Arab, dan wanita-wanita selain Arab juga wajib mengenakan jilbab. Muhammad 'Ali Al-Shabuni memahami asbabunnuzul ayat tersebut secara tekstual. Maka dari itu beliau tidak hanya mewajibkan seorang muslimah yang di Arab maupun wanita selain Arab cukup untuk memakai jilbab, akan tetapi mereka wajib memakai cadar. Hal ini dikarenakan bunyi teks ayat ini dan juga asbabunnuzul ayat ini memerintahkan seorang wanita untuk memakai cadar.

Sedangkan Muhammad Quraish Shihab dalam memahami Q.S. Al-Ahzab ayat 59, menggunakan kaidah tafsir al-'ibrah bi khusush al-sabab la bi 'umum al-lafzh. Maka dari itu beliau berpandangan bahwa ayat tersebut hanya berlaku untuk orang-orang yang terlibat dalam latar belakang ayat itu diturunkan, dan orang Arab saja, selain wanita Arab tidak wajib mengenakan cadar dan jilbab. Asbabunnuzul ayat ini dipahami secara kontekstual dengan memperhatikan kondisi masyarakat Arab yang pada waktu ayat ini turun, notabene-nya mereka sudah mengenakan jilbab, akan tetapi rambut, kepala, leher dan dada mereka masih terlihat.

Fenomena yang ada pada masyarakat Arab sangat berbeda dengan masyarakat Indonesia yang majemuk. Di Indonesia tidak ada perbudakan, tentu saja tidak ada perbedaan pakaian, antara pakaian wanita merdeka dan budak. Bisa saja perintah menggunakan hijab yang ada dalam Q.S. Al-Ahzab ayat 59 yang khitab-nya adalah wanita Arab, tidak berlaku pada masyarakat non Arab, terutama di Indonesia. Namun pendapat ini bertentangan dengan hadits yang diriwayatkan oleh 'Aisyah R.A yang menyatakan bahwa Rasulullah SAW memerintahkan wanita yang beriman jika sudah baligh hendaknya menutup seluruh tubuhnya, kecuali wajah dan kedua tangan.

Ayat tersebut berlaku secara universal karena Islam rahmatan lil 'alamin, maka hukum yang berlaku tidak hanya untuk masyarakat Arab, akan tetapi berlaku untuk semua wanita yang beriman di muka bumi ini. Jika yang terlihat hanya dada, leher, dan rambut wanita saja bisa memancing nafsu birahi kaum pria, apalagi jika bagian tubuh yang lain ikut terlihat. Jelas hal ini akan menimbulkan kerusakan moral yang lebih parah pada masyarakat dewasa ini, dibandingkan dengan kondisi masyarakat Arab jahiliyah dahulu. Maraknya kasus pelecehan seksual terhadap wanita dewasa ini, baik di tempat-tempat umum, di bis, di angkot, dikarenakan wanita-wanita tersebut memakai pakaian yang minim, sehingga memicu gejolak syahwat lawan jenis.

\section{KESIMPULAN}

Perintah menggunakan jilbab merupakan suatu kewajiban bagi seorang muslimah. Hasil pengamatan penulis terhadap dua tokoh tafsir yaitu Muhammad 'Ali 
Al-Shabuni dan Muhammad Quraish Shihab ternyata terdapat perbedaan penafsiran keduanya terhadap ayat-ayat tentang jilbab dan cadar.

Muhammad 'Ali Al-Shabuni dalam memahami Q.S. Al-Ahzab ayat 59 ini menggunakan kaidah tafsir al-'ibrah bi 'umum al-lafzh wa bi khushush al-sabab. Jadi, ayat ini berlaku untuk orang-orang yang terlibat dalam latar belakang ayat itu ketika diturunkan, yaitu wanita-wanita Arab, dan wanita-wanita selain Arab juga wajib mengenakan jilbab. Muhammad 'Ali Al-Shabuni memahami asbabunnuzul ayat tersebut secara tekstual. Maka dari itu beliau tidak hanya mewajibkan seorang muslimah yang di Arab maupun wanita selain Arab cukup untuk memakai jilbab, akan tetapi mereka wajib memakai cadar. Hal ini dikarenakan bunyi teks ayat ini dan juga asbabunuzul ayat ini memerintahkan seorang muslimah untuk memakai cadar.

Muhammad Quraish Shihab dalam memahami Q.S. Al-Ahzab ayat 59, menggunakan kaidah tafsir al-'ibrah bi khushush al-sabab la bi 'umum al-lafzh. Maka dari itu beliau berpandangan bahwa ayat tersebut hanya berlaku untuk orang-orang yang terlibat dalam latar belakang ayat itu diturunkan, dan orang Arab saja, selain wanita Arab tidak wajib mengenakan cadar dan jilbab.

Sebagai akademisi hendaknya menyikapi dan menerima perbedaan penafsiran kedua tokoh tersebut dengan tanpa menyalahkan salah satu di antara keduanya. Kedua tokoh di atas telah menafsirkan ayat Al-Qur'an sesuai dengan ilmu tafsir. Hanya saja Muhammad 'Ali Al-Shabuni menggunakan pendekatan penafsiran tekstual, sedangkan Muhammad Quraish Shihab menggunakan pendekatan penafsiran kontekstual.

\section{REFERENSI:}

Abu Dawud, Sunan Abi Dawud (Tahqiq Muhammad Muhyi al-Din 'Abd al-Hamid) Beirut: Dar al-Fikr, t.th.

Al-'Asqalani, Shihabuddin Abi al-Fadl Ahmad bin 'Ali bin Muhammad bin Hajar, Fath al-Bari bisharah Shahih al-Bukhari Kairo: al-Maktabah al-Salafiyah, t.th., jilid 8.

Al-Asbahi, Abu 'Abd Allah Malik bin Anas bin Malik bin Abu 'Amir (Tahqiq Muhammad Fu'ad 'Abd al-Baqi), al-Muwaththa' Beirut: Dar Ihya' al-Turath al'Arabi, t.th., jilid I.

Al-Baidlawi, Nashir Al-Din Abu Sa'id Abd Allah Ibnu 'Umar bin Muhammad alSayrazi, Tafsir Al-Baidlawi, Beirut: Dar al-Kutub al-`Ilmiyah, 1971.

Al-Bukhary, Shahih Al-Bukhary, Beirut: Dar Ibn Kathir al-Yamamah, 1987/1407, Cet III.

Al-Nawawi, Sharah Al-Nawawi 'ala Shahih Muslim, Beirut: Dar al-Kutub al-'Alamiyah, t.th., jilid 10.

Al-Qurthuby, al-Jami' li Ahkam al-Qur'an, Cairo: Dar Sha'b, 1372 H, Cet. II, XII.

Al-Shabuni, Muhammad 'Ali, Cahaya Al-Qur'an Jakarta: Pustaka Al-Kauthar, 2002, Jilid 5 . 
Al-Shabuni, Muhammad 'Ali, Rawai' al-Bayan Tafsir ayat al-Ahkam min al-Qur'an Jakarta: Dar al-Kutub al-Islamiyyah, 1999.

Al-Shabuni, Muhammad 'Ali, Shafwah al-Tafasir Kairo: Dar al-Shabuny, 1980.

Al-Tirmidhi (Tahqiq Ahmad Shakir wa Jama'ah), Sunan Al-Tirmidhi Beirut: Dar Ihya' al-Turath al-'Arabi, t.th.

Al-Wahidi, Abu al-Hasan 'Ali bin Ahmad bin Muhammad bin 'Ali . Asbab Nuzul alQur'an Kairo: Maktabah al-īman, 1996.

Ghazali, Abd. Moqsith, et.al.,Metodologi Studi Al-Qur'an. Jakarta: Gramedia, 2009.

Ibnu Ashur, Muhammad Thahir , Tafsir al-Tahrir wa al-Tanwir, XXII, 10

Ibnu Kathir, Abu al-Fida' Isma'il bin 'Umar ( Tahqiq Shafi al-Rahman alMubarakfuri), Mukhtasar Tafsir Ibnu Kathir Riyad: Muntada al-Thaqafah, 2013, cet. I.

Maggalatung, A.S.; Aji, A.M.; Yunus, N.R. How The Law Works, Jakarta: Jurisprudence Institute, 2014.

Moleong, Lexy J., Metodologi Penelitian Kualitatif (Bandung: PT. Remaja Rosda Karya, 2004

Rezki, Annissa; Anggraeni, RR. Dewi; Yunus, Nur Rohim. "Application of Civil Law Theory In the Termination of Custody of Adopted Children in Indonesia," Journal of Legal Research, Volume 1, No. 6 (2019).

Shihab, Muhammad Quraish, Membumikan al-Qur'an: Fungsi dan Peran Wahyu dalam Kehidupan Masyarakat (Bandung: Mizan, 1999.

Shihab, Muhammad Quraish, Mu'jizat al-Qur'an Ditinjau dari Aspek Kebahasaan, Isyarat Ilmiah dan Pemberitaan Gaib (Bandung: Mizan, 2001.

Shihab, Muhammad Quraish, Tafsir al-Mishbah, Pesan, Kesan, dan Keserasian al-Qur'an, Jakarta: Lentera Hati, 2002, Vol. 10.

Shihab, Muhammad Quraish, Tafsir al-Mishbah, Pesan, Kesan, dan Keserasian al-Qur'an, Jakarta: Lentera Hati, 2002, Vol. 9. 